\title{
Presence of fatty liver disease leads to unusual rise of liver enzymes in patients with common bile duct colic
}

\author{
Buddhika URAGODA ${ }^{*, 1}$, Dileepa EDIRIWEERA', Lakmali PARANAHEWA², \\ Chanaka EKANAYAKE' ${ }^{1}$, Suchintha TILLAKARATHNA', Rohan SIRIWARDANA \\ 'Department of Surgery, Faculty of Medicine, University of Kelaniya, Ragama, Sri Lanka \\ ${ }^{2}$ Department of Radiology, Asiri Surgical Hospital, Colombo, Sri Lanka
}

Introduction: This study compares liver enzymes, inflammatory markers and bilirubin levels in patients with and without fatty liver disease (FLD) presenting with common bile duct (CBD) obstruction.

Methods: CBD colic was diagnosed based on clinical, radiological and biochemical criterion. Presence of FLD was diagnosed by ultra sound scan and the macroscopic appearance of liver during surgery. Liver enzymes, inflammatory markers and bilirubin levels were prospectively assessed and compared between the two groups.

Results: Out of 42, there were 22 (52.3\%) patients with FLD. Median body mass index was 26.9 (24.1-30.8) in fatty liver group compared to 25.7 (23.5-26.2) in others. Individuals with FLD showed high aspartate transaminase (558.5 vs. 247.0, $p=0.005)$, alanine trasaminase (467 vs. $228.5, p=0.005)$ and bilirubin (3.8 vs. $2.2, p=0.015$ ) levels compared to those without FLD. According to multiple linear regression models, high AST and ALT levels showed significant associations with FLD after adjusting for age, gender, body mass index, amylase and $\mathrm{C}$ reactive protein levels. The median enzyme level at two weeks did not show a difference among patients with and without FLD.

Conclusions: Presence of FLD causes unusual rise of AST and ALT levels in patients with CBD stones. This rise is transient. 